\title{
Ludwig's angina
}

\author{
Kael Duprey • Jonathan Rose • Christian Fromm
}

Received: 3 February 2010 / Accepted: 19 February 2010/Published online: 8 June 2010

(C) Springer-Verlag London Ltd 2010

Patients with Ludwig's angina require urgent evaluation for airway obstruction due to elevation and posterior displacement of the tongue. Emergency physicians should remember that risks of laryngospasm preclude blind oral or nasotracheal intubation.

A 54-year-old female presented to the emergency department (ED) with right-sided facial pain, subjective fever, and chills for 1 week. Physical examination revealed right-sided facial swelling, trismus, tongue elevation (Fig. 1), submandibular and sublingual swelling, and tenderness with adenopathy. Computed tomography (CT) findings were (Fig. 2) consistent with Ludwig's angina. The patient was

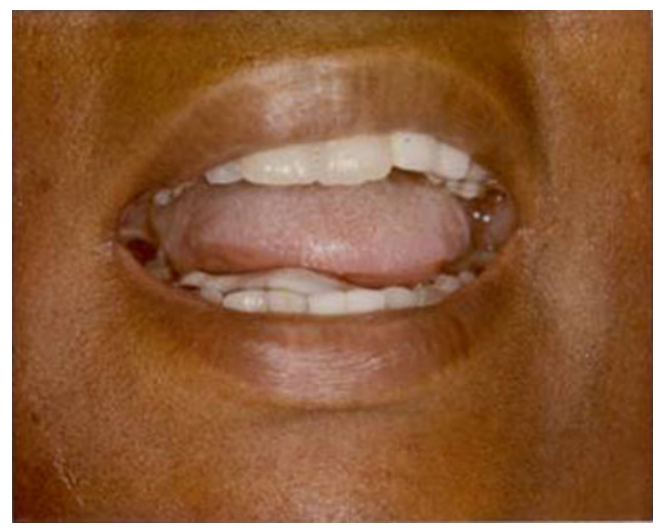

Fig. 1 Clinical appearance

\footnotetext{
K. Duprey $(\bowtie) \cdot J$. Rose $\cdot$ C. Fromm

Department of Emergency Medicine,

Maimonides Medical Center,

4802 Tenth Avenue,

Brooklyn, NY 11219, USA

e-mail: KDuprey@maimonidesmed.org
}

treated with dexamethasone and clindamycin, and taken for surgical decompression and tooth extraction then discharged home. Pathological analysis showed polymicrobial flora including Staphylococcus aureus, Eikenella corrodens, Clostridium clostridiforme, and Prevotella buccae.

Ludwig's angina, a rapidly progressive cellulitis of the floor of the mouth, involves the submandibular, submaxillary, and sublingual spaces. Patients have swelling, pain, and elevation of the tongue, malaise, fever, neck swelling, and dysphagia. The submandibular area can be indurated, sometimes with palpable crepitus. Inability to swallow saliva and stridor raise concern because of imminent airway

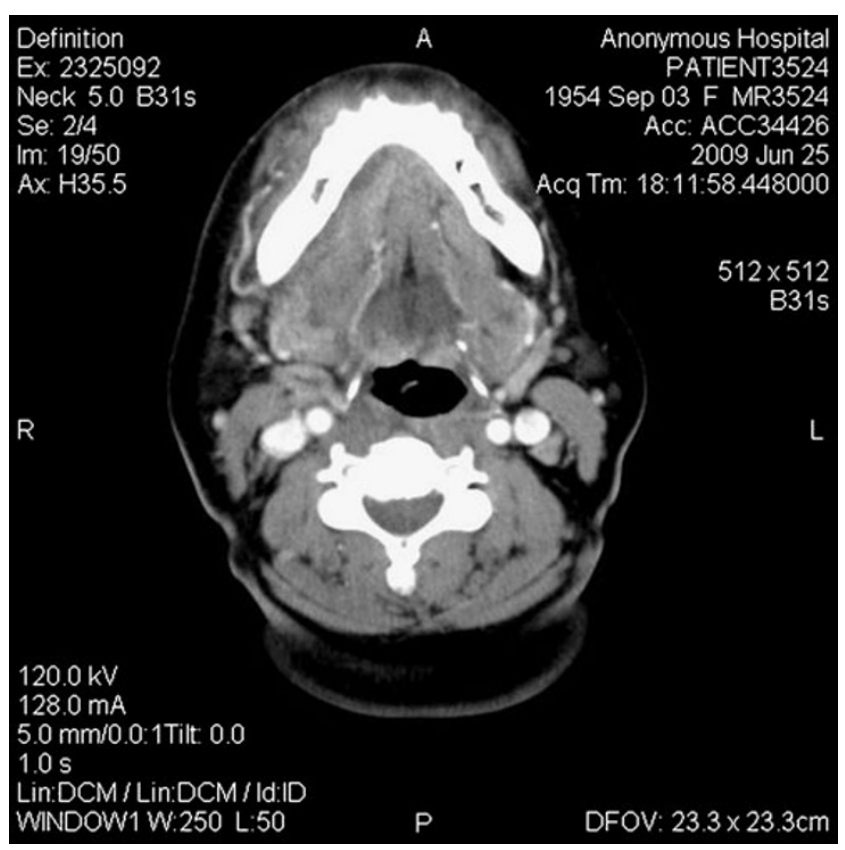

Fig. 2 Computed tomography findings 
compromise. The most feared complication is airway obstruction due to elevation and posterior displacement of the tongue. The mortality rate for Ludwig's angina is currently below $8 \%$ down from the preantibiotic numbers over $50 \%$ [1].

Nasal fiberoptic evaluation should be performed with imminent airway obstruction. Securing the airway by blind oral or nasotracheal intubation is contraindicated because of the risk of laryngospasm. Diagnostic sensitivity of clinical examination alone is $55 \%$. In less urgent cases, contrastenhanced CT may increase this to $95 \%$ [2]. Immunocompetent patients should receive ampicillin-sulbactam, with clindamycin reserved for penicillin-allergic patients. Immunocompromised patients require empiric broad-spectrum antibiotics. Any source of infection should be removed.
Needle drainage can be performed to reduce the risk of spreading infection [3].

\section{References}

1. Moreland L, Corey J, McKenzie R (1988) Ludwig's angina: report of a case and review of the literature. Arch Intern Med 148:461466

2. Miller WD, Furst IM, Sandor GK, Keller A (1999) A prospective blinded comparison of clinical exam and computed tomography in deep neck infections. Laryngoscope 109:1873-1879

3. Bross-Soriano D, Arrieta-Gomez JR, Jorba-Basave $\mathrm{S}$ et al (2004) Management of Ludwig's angina with small neck incisions: 18 year experience. Otolaryngol Head Neck Surg 130:712-717 